\title{
JOARTAN WEDERGEVONDEN?
}

DOOR

\author{
R. A. KERN.
}

I.

Onder dezen titel, zonder het vraagteeken, heeft J. Hageman reeds vele jaren geleden in het Tijdschrift van het Bataviaasch Genootschap een artikel geschreven ten betooge dat hij het Jortan der oude Hollanders in het Javaansche Pĕdjarattan, Djaratan had wedergevonden ${ }^{1}$ ). - De schrijver putte deze kennis uit een Salasila[h] Garsik, te zijner tijd in manuscript bestaande maar waarvan verder niets bekend is. Daarin wordt gezegd: ,njai-gedée Panaté, eene vrouw „van buiten' Java gekomen, weduwe en voorname handelares, bezat ,,veel vaartuig en hare woonplaats vormde een eigen kampong aan „zee, bij Kissiek; thans eene plaats ongeveer twee honderd roeden „,beoosten de „kotta Garsik” en noord van de begraafplaats Gapoero”.

„Die handelswijk werd door de handelaren van buiten genaamd „Djaratan, Pědjarattan, en van lieverlede kwamen vele kooplieden ,zich hier nederzetten.” ${ }^{2}$ ).

Elders vertelt de zelfde schrijver van deze vrouw dat zij zich te Grěsik nederzette met het voornemen zich in de Mohammedaansche leer te volmaken ${ }^{3}$ ).

Dit verhaaltje heeft kennelijk ten doel de stichting van Grěsik (ook: Garsik, Gĕrěsik, Gĕrsik) te verklaren. Immers, Jav. g is i k, gĕgi sik, kisik, kěkisik is ,strand, zeestrand”, Mal. kĕrsik grind, grof zand, Bat. horsik - idem, Mak. kass i', Boeg. kĕssi' zand, zeestrand, Soend. kösik - grind. Er kan dus geen sprake zijn van een zich vestigen op een plaats beoosten Grěsik aan zee, het Kissiek van Hageman is Grěsik en inderdaad strekt de stad zich tot aan zee uit. De begraafplaats Gapoera (wetan) ligt in het Zuid-Oosten der stad. Daartoe geeft een poort (gapoera) in Hindoe-Javaanschen stijl toegang, zij is vermaard omdat er zich de graftombe van Malik

1) Tijdschr. Batav. Gen., dl. 17, blz. 367 v.v.

2) T.a.p., blz. 368 .

3) Indisch Archief II 219. - Batavia 1850. 
Ibrahim $\dagger 1419$ bevindt. Den naam Gapoera heeft de begraafplaats vermoedelijk pas gekregen toen de poort een bouwwerk uit het verleden was geworden. Men schijnt onder de handelswijk waarvan de salasilah zegt dat haar de naam Djaratan, Pědjarattan gegeven werd, de eigen kampong van njai gěde Panate te moeten verstaan, dus iets anders dan de begraafplaats Gapoera.

Djaratan of padjaratan is afgeleid van Arabisch zijarah - bezoek (aan een graf), in den vorm djarat, $\mathrm{dj}$ irat enz. in verschillende, Indonesische talen overgegaan, met de beteekenis ,graf, begraafplaats"; het woord stamt dus uit den Mohammedaanschen tijd, padjaratan of, verkort, djaratan is bepaaldelijk ,grafstede". Nu kan het wel zijn dat men het graf van Malik Ibrahim of van een ander met den naam $\mathrm{p}$ a d j a r a t a n, d j a rat a n bestempelt, maar de Javanen noemen hun steden en ook hun handelswijken niet „,begraafplaats”, daargelaten dat het tot den Javaanschen taalschat behoorende djaratan noch door de Javanen ter plaatse noch door de Nederlandsche zeevaarders tot Joartan verhaspeld kan zijn. Een kampong $(\mathrm{Pa})$ djaratan komt op de Topografische kaarf - welke de namen der kampongs vermeldt - niet voor ${ }^{1}$ ).

De naam Ioartan, Iortan is ons bekend geworden uit de scheepsjournalen en koopmansgeschriften der eerste Nederlandsche Oostinjevaarders. In de Historie van Indien / waar inne verhaelt is de avontueren die de Hollandsche Schepen bejeghent zijn : etc., het befaamde, door Willem Lodewycksz opgestelde reisverhaal der eerste schipvaart onder Cornelis de Houtman, komt een capittel voor: Van de afcomste der Iauwen ende hare steden ${ }^{2}$ ). Lodewycksz heeft hierin opgenomen wat hij te weten kon komen, het berust niet op eigen waarneming maar is tweedehandsche kennis, men vindt er rijp en groen dooreen. Juist in de beschrijving der steden langs Java's Noordkust, van Pasoeroehan tot Sidajoe lawas, is het verhaal danig in de war. Er wordt van Ioartan o.m. gezegd dat de stad aan een schoone rivier ligt en ommuurd is. Noch het een noch het ander was het geval. De eenige rivier in deze contreien is de Kali Lamong, welke drie paal ten Zuiden van Grěsik in zee stroomt, de muur ziet op Grĕsik, zooals hieronder zal blijken.

Op de eerste reis van Jacob van Neck en Wybrandt van Warwijck hebben de Nederlanders Joartan het eerst aanschouwd: 27 Januari

1) Topografische kaart residentie Soerabaja, bijgewerkt tot 1892, schaal $1: 20000$, détailbladen K VI, VII, L, VI, VII (Grĕsik en omstreken).

2) Linschoten Vereeniging VII 99 v.v. 
1599 verscheen de vloot voor ,het stedeken" Ioartan ${ }^{1}$ ). Bizonderheden worden niet meegedeeld. Doch Jacob van Heemskerck, die de reis meemaakte, heeft een memorie opgesteld over de wijze waarop, naar zijn bevinding, op de kustplaatsen van Java en in de Molukken de handel moest gedreven worden ${ }^{2}$ ). Hij zegt daarin: ,Jurtan is de „,bequamste ende beste haven in geheel Java, alwaer meest alle den „,handel van de specerijen, als nooten, fuly ende nagelen gedaen wert, ,waermede de Poortugesen haer seer wel weeten te behelpen, hebben ,meest alle coopmanschap bij haer, die de Javanen gebruycken ende ,,vervoeren alsoo mede casies ${ }^{3}$ ), hetwelcke sy aen de Javanen uitdoen „op de reys, ende bodemery van het gaen ende wederkeeren naer „Moluco ofte Banda, waervoor de ontfangers bij geschrifte borch „stellen, ende nadat ick van de Portugesen verstaen hebbe weynich „faute aen de betalinge.... is genoechsaem een beslooten haven, ende ,men can op 12 vadem op een steenworp van de muren van de stadt „Grisse, twelck de prinsepale stadt-is, met groote scheepen leggen”. De sabandar woont aldaar. M.a.w. Joartan paalde aan Grěsik maar lag buiten de muren. Hier kwamen de schepen ten anker. Van Heemskerck geeft hier in weinige zinnen een schitterende beschrijving van de Molukken-vaart der Javanen en de beteekenis van Joartan. Wat hij over den handel ter plaatse zegt, vindt volledige bevestiging bij Coen. In diens tijd was alles nog bij hetzelfde. Men behoeft zijn brieven aan heeren meesters in patria - wien hij de les leest of aan zijn varende of gezeten ondergeschikten in den Archipel slechts door te bladeren om in te zien dat Joartan het uitgangspunt van den handel op de Molukken was ${ }^{4}$ ). Buiten de specerijen uit den Grooten Oost werd ook peper uit Djambi aangebracht, doch hierin bezat de plaats geen monopolie-positie, Bantěn en Djapara traden, mede door toedoen van Europeesche handelaren, als concurrenten op.

In de Beschryvinghe van de Voyagie, ghedaen door Olivier van Noort, die, na de halve aardbol te zijn omgezeild, van uit de Filip-

1) Begin ende Voortgangh I, Reis 3, blz. 13.

2) $\mathrm{Bij}$ de Jonge, Opkomst II 448 v.v., het aangehaalde vindt men op blz. 451 v.v.

3) Port caix a s; van Linschoten geeft op dat ,in de Sunda” waarmee o.a. Java bedoeld is, anders geen geld is dan koperen caixas, het bekende, Chineesche geld met vierkant gat in het midden; hij stelt de waarde van 1000 caixas op een Portugeesche crusado of 3 Carolus-guldens Nederlandsche munt, Itinerario, Linschoten Vereeniging III 78.

4) H. T. Colenbrander, Jan Pietersz. Coen. Bescheiden omtrent zijn bedrijf in Indië, 5 deelen, passim. - 's-Gravenhage 1919-'23. 
pijnen met zijn eenig overgebleven schip in 1601 ter reede kwam, wordt gezegd: „Dese Stadt van Ioartan leyt aen den watercant op „een punckt, in deselve moghen ontrent 1000. Huysen staen, al van „Hout ghemaeckt, ten heeft geen Muragie” ${ }^{1}$ ). - Wanneer de kustlijn sedert niet veranderd is, zou deze punt de plaats zijn waar nu de desa Kaboengson ligt, iets ten Noorden van het laadhoofd te Grěsik.

De Nederlanders hadden, vooral in den beginne, de gewoonte van Joartan te spreken. Later zei men vaak Grěsik (meestal Grissee, wat nog de Hollandsche uitspraak is), dikwijls vindt men beide namen dooreen of tesamen gebruikt. Allen bedoelen hetzelfde: de stad Grěsik met haar havenkwartier Joartan. De laatste naam is in onbruik geraakt. Wat Valentijn ervan zegt, klinkt als een zwakke nagalm ${ }^{2}$ ).

Ioartan, slordiger Iortan, beantwoordt aan Jav. $\mathrm{D}$ j o e w a $\mathrm{rtan}$; Jav. $d j$ sprak men als $j$ uit en schreef $j$ of $i$, Jav. oe wordt geregeld met $o$ weergegeven (Japara $=$ Djapara, Joana $=$ Djoewana). In het Nieuw-Javaansch gaat $a$ in de derde lettergreep van achteren vóór $w$ in oe over: Oud-Jav. ka w a li, Nieuw-Jav. koewali - pan; Oud-Jav. kawaça, Nieuw-Jav. koewasa - machtig, enz. De oudere uitspraak van Djoewartan is dus D j a w a rta n. In het NieuwJavaansch komt in plaats- en eigennamen $d j a{ }^{\circ}$ naast $\mathrm{dja} j \mathrm{a}$ - overwinnend, zeeghaftig, voor; in het K.B.Wb. s.v. wartta (uitgesproken warta) vind ik een aanteekening van mijn Vader, ,goed in orde" (w ā rtta), doch wat is $-n$ ? Ik houd het ervoor dat Djawartan of, naar de voor het Oud-Javaansch aangenomen schrijfwijze die ik hier verder zal behouden: Jawartan, staat voor Jawartam en dit op een Tamil $\mathrm{Ja}(\mathrm{ya})$ warttam teruggaat. In het algemeen kan een woord in het Tamil niet met een muta beginnen doch in woorden die uit het Sanskrit zijn overgenomen wordt $j$ somtijds gehandhaafd ${ }^{3}$ ). Voorts is bekend dat bij vele overgenomen Sanskritwoorden aan het slot een $m$ wordt toegevoegd. $\mathbf{M} \bar{a}^{\circ}$ is in samenstellingen een gewone syncope van Skr. $\left.m a h \bar{a}^{04}\right)$. 't Zou kunnen zijn dat van $\mathrm{ja}^{\circ}$,

1) Olivier van Noort, Reis om de wereld (1598-1601), Linschoten Vereeniging, XXVII 141 v.v.

2) „Even zoodanig plagt ook Gressic Ao. 1609 niet alleen mede; maar Ao. „1601, zelf ook Joartan, Passaroewan, en Balamboang . . . dezen Koning [van "Soerabaja] onderdanig te zijn", Valentijn IV/I 48.

$\left.{ }^{3}\right) \mathrm{R}$. Caldwell, A comparative grammar of the Dravidian . . languages, $2 \mathrm{e}$ druk, blz. 24. - Londen 1875.

4) G. Coedès, Le royaume de Çrīvijaya, B. E. F. E. O.T. XVIII no. 6, blz. 10 van den overdruk. 
Skr. j a y a hetzelfde geldt, ik moet dit uit onbekendheid met het Tamil in het midden laten. In het Oud-Javaansch komt $\mathrm{ja}^{\circ}$ als syncope van $\mathrm{j}$ a y a bij mijn weten niet voor. Wanneer $\mathrm{ja}{ }^{\circ}$ dus geen Tamil is, moet het eerste element van den naam eertijds jaya geweest zijn en later (in het Javaansch) tot $\mathrm{ja}$ - zijn verkort. - 't Komt in het Javaansch hoogst zelden voor dat een woord op $t$ a $\mathrm{m}$ uitgaat, het eenige mij bekende voorbeeld is $\mathrm{r}$ a n t a m gw. v. ,,vooraf regelen". Daarentegen is het locatief suffix - a n bij plaatsnamen zeer gewoon: Parakan - plaats waar men een rivier afdamt (gw. parak), Pikatan - plaats waar men vogels vangt, met een lokvogel (gw. pikat) enz. 't Behoeft dus niet te verwonderen dat de Javanen $\mathrm{Ja}$ (ya)wārttam tot $\mathrm{Ja}(\mathrm{ya}$ ) wartan hebben gejavaniseerd.

Wat $\mathrm{j}$ a - betreft, kan men uit lateren tijd nog vergelijken $\mathrm{D} \mathrm{j} \mathrm{a} \mathrm{-}$ k ět ra (Jakětra), bekend als de plaats waar Batavia verrees ${ }^{1}$ ).

Ik meen Jawartan te herkennen in een bericht in de nieuwe geschiedenis der T'ang dynastie: „During the period Chin-kwan ,,627-649) this country [Ka-ling] sent envoys to bring tribute, ,together with those of Dva-ha-la and Dva-pa-tan" $\left.{ }^{2}\right)$. En in de oude geschiedenis der T'ang dynastie wordt nog gezegd: „In the year 647 their king (van ,the country of Dva-pa-tan”) sent envoys to bring tribute" enz. ${ }^{3}$ ). Dva-pa-tan beantwoordt het naast aan Jawartan, maar zou ook voor Jayawartan kunnen staan. Een op $-m$ uitgaande syllabe wordt in het Chineesch meermalen door een op - $n$ eindigend woord weergegeven,bv. $\left.\mathrm{Kou}-\mathrm{in}=\mathrm{Coilam}{ }^{4}\right), \mathrm{T} \mathrm{h}$ an $\left.=\mathrm{Cham} .(\mathrm{Tjam})^{5}\right), 1 \ddot{\mathrm{u}}-\mathrm{kan}=$ Ar. Perz. rukhām - marmer,

1) Dit is de juiste naam, niet Djakarta; k ĕ tra $=\mathrm{k}$ ĕ r ta, ka r ta, k r ět a - geregeld, in orde gemaakt, gelukkig, voorspoedig, de naam is dus synoniem met Jawartan. In aanmerking genomen dat de Hollanders van de Javaansche $\mathrm{dj}^{\prime}(\mathrm{j}) \mathrm{j}(\mathrm{y})$ makkten - en wie niet beter weten doen dat nog - en de neiging bestaat in Indonesische, drielettergrepige woorden de klemtoon op de eerste

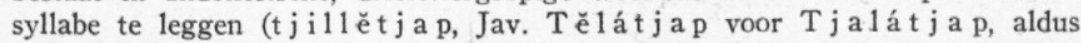
nog in het Soendaasch, bándjaran voor Bandjáran enz.) is Jaccatra een vrij zuivere weergave van Djakětra. Wil men de proef op de som: tot een jong Europeesch kind dat Nederlandsch kende maar bij voorkeur Maleisch sprak, werd eens gezegd: „Wij gaan naar den weg van Jaccatra”. Onmiddelijk zette het dit om in Djakětra. De naam komt ook in Midden-Java (Panggoel) voor.

2) W. P. Groeneveldt, Notes on the Malay Archipelago and Malacca compiled from Chinese sources. Reprint 1887, blz. 139.

3) O.c.p. 183.

4) P. Pelliot, Deux itinéraires, B. E. F. E. O. T. IV 319.

5) O.c.p. 200. 
albast $\left.^{1}\right)$. Er is dus geen bezwaar tegen de gelijkstelling Dva-pa-tan$\mathrm{Ja}(\mathrm{ya})$ wārttam.

Van Dva-pa-tan wordt verder verhaald dat het ten Oosten van Ka-ling lag. Er wordt algemeen aangenomen dat deze naam ergens in Midden-Java is te zoeken, ten aanzien van Dva-pa-tan wordt dan aan Bali gedacht. Zoo deed reeds Groeneveldt, doch onder voorbehoud. Krom heeft opgemerkt dat de bewoordingen niet noodzakelijk dwongen aan een ander eiland te denken, er staat slechts dat Ka-ling ten Westen van Dva-pa-tan ligt, het kan dus ook in Oost-Java te zoeken zijn $^{2}$ ).

De oude geschiedenis der T'ang dynastie bepaalt de ligging als volgt: „The country of Dva-pa-tan is situated to the south of Cam„boja, at a distance of two months, going by sea. It lies at the east of „Kaling and the west of Mi-li-kü, on its north it has the sea" ${ }^{3}$ ). Onder Mi-li-kü moet, ondanks de verschillende vocaliseering, wel Maloku, de Molukken, verstaan worden. In hetzelfde geschrift wordt Ka-ling beschreven als liggende op een eiland in den Zuidelijken Oceaan, ten Oosten van $\mathrm{Pa}-\mathrm{li}$ of Po-li, ten Westen van Dva-pa-tan (Groeneveldt o.c.p. 138). Pelliot heeft deze lezing verbeterd, er staat: „Ten Oosten raakt het (Ho-ling) aan P'o-li, ten Westen aan T'op'o-teng (= Dva-pa-tan bij Groeneveldt) (Deux itinéraires p. 280). De oude geschiedenis der T'ang-dynastie is hier in strijd met zichzelf, immers, onder Dva-pa-tan wordt gezegd dat Ka-ling ten Westen ligt. Blijkbaar zijn Oost en West in de aanteekening over Ka-ling verwisseld, daar de juistheid van Dva-pa-tan's ligging ten Westen der Molukken niet betwijfeld worden kan en dus ook niet die ten Oosten van Ka-ling. Doch als Ka-ling Dva-pa-tan ten Oosten heeft, heeft het Pali of Poli ten Westen. Groeneveldt's vertaling, hoewel als zoodanig onjuist, geeft dus toch weer wat bedoeld wordt. Pali is niet geidentifceerd, wij zien thans bevestigd dat het ten Westen van Java gezocht moet worden. Alleen afgaande op hetgeen ervan gezegd wordt, lijkt een ligging ergens op Sumatra ${ }^{4}$ ) reeds waarschijnlijker dan Bali.

1) Bij Chau Ju-kua; uitgave Hirth en Rockhill, blz. 115. - St. Petersburg 1911.

2) N. J. Krom, Hindoe-Javaansche geschiedenis, blz. 102. - 's-Gravenhage 1926.

3) Groenevelt o.c.p. 183 .

4) Of Groot-Bangka, omvattende Bangka, Balitoeng en omliggende eilanden? (V. Obdeyn, De oude zeehandelsweg door de Straat van Malaka in verband met de geo-morfologie der Sělat-eilanden, in Tijdschr. Aardrijksk. Gen., 2e 
't Is begrijpelijk dat de eerste Nederlanders die de reede bevoeren de stad naar de plaats waar zij ankerden noemden, evenzeer dat van lieverlede Grěsik in hun berichten meer naar voren kwam. De Portugeezen kenden den naam Djoewartan, de Portugees die, volgens Rouffaer, Willem Lodewycksz inlichtte, sprak van Djoewartan ${ }^{1}$ ), maar zij waren in de 16e eeuw gewoon de plaats Agaçim $=$ Garsik, te noemen ${ }^{2}$ ).

De naam is oud. In de nieuwe geschiedenis der T'ang dynastie (618 - 906) wordt gezegd dat de voorvader des konings (van Chöp'o), Ki-yen bij name, naar het Oosten, naar de stad P'o-lou-kia-sseu verhuisde. Het tweede deel van dezen naam beantwoordt aan Gar$\mathrm{sik}^{3}$ ) ; het eerste is Waru. Dit ligt aan den grooten weg van Soerabaja naar Sidaardja bij paal 10. Er staat dus dat Ki-yen verhuisde naar Waru, met de toevoeging Garsik ter nadere bepaling. Waru (Hibiscus tiliaceus) is een zeer gewone plaatsnaam. Pelliot, wiens lezing ik hier volg, zegt dat hij ,émigra” (o.c.p. 225), in een noot op dezelfde bladzijde geeft hij de vertaling ,a transporté (la capitale) ,,vers l'est”. Uit een ander werk, de Ying houan tche lio, wordt dan aangehaald: ,on deplaça (la capitale) de Chö-p'o à la ville de P'olou-kia-sseu, gesteld in de periode 742-755. Pelliot plaatst ,la capitale” tusschen haakjes, ik maak hieruit op dat ts'ien in beide gevallen een intransitieve vertaling toelaat: „émigra”, als ook in den tekst gezegd.

Ki-yen is m.i. niets anders dan kry a n - prins, edele, het honorifiek voorvoegsel $r a$, Chin. weergave $l o$, is weggelaten $\left.{ }^{4}\right)$. Rakry a n komt in Oud-Javaansche oorkonden vanaf het midden der 9e eeuw tallooze malen als titel van hoogwaardigheidsbekleeders voor, doch nimmer van een regeerend vorst. Hierop ken ik slechts één schijnbare uitzondering : in een oorkonde op koper (dateering onleesbaar) van koning Wawa,

Serie, dl. LIX, bl. 757 v.v. - De prealabele vraag is of deze door zeestraten doorsneden eilandengroep toentertijd één uitgebreid landgebied was, een vraag alleen door geologen op te lossen.

1) Linschoten Vereeniging VII 99 noot 1, 101. vgl. boven blz. 2.

2) P. A. Tiele, De Europeërs in den Maleischen Archipel I, 1500-1529, in: Bijdr. Kon. Inst. 4, I, 356 noot 1.

3) Andere weergaven van den naam zijn: Kĕ-r-sih, in: Ying-yai Shêng-lan (1416), Groeneveldt o.c.p. 173 noot, en Ki-li-sik, in: Tung Hsi Yang K'au (1618), Groeneveldt p. 179.

4) Vrg. Lo-ki-lien, in de geschiedenis der Sung dynastie (960-1279), Groeneveldt o.c.p. 143, Krom o.c.p. 283. - Vgl. Mak. k a r a e n g - vorst, landsgroote, Heer van, Tag. da y a n g. Sp. doña. 
van wien oorkonden bekend zijn uit de jaren 924-929, wordt hij „,anak kryan ladheyan sang lumah ring alas" genoemd; kryan is reeds verdacht, de titel luidt altijd $\mathrm{r}$ a kry a n. De oorkonde is ons alleen in een verknoeide copie bewaard, zij mist bewijskracht ${ }^{1}$ ).

Een en ander voert tot het besluit dat tusschen de jaren 742 en 755 een aanzienlijk heer, wellicht een prins van den bloede, van Midden-Java naar Waru verhuisde, maar niet als vorst. Men zou hem zich ook moeilijk als zoodanig in Waru kunnen denken. Immers, een regeerend vorst treffen wij in den Oosthoek in 760 op den steen van Dinaya aan. Naast hem schijnt voor een koning in Waru geen plaats.

Op ongeveer 2 paal zuidwestelijk van Waru ligt Kěboan pasar, alwaar een oorkonde op koper ${ }^{2}$ ) van 873 gevonden is, handelende over het afbakenen van een vrijgebied Waharu door zekere(n) sanghadyan Kuluptiru tot erfelijk bezit van zijn (of haar) nageslacht ${ }^{3}$ ). De beschikker (beschikster) is dus een adellijk heer of edelvrouw, geen vorst, mogelijk een nazaat van Ki-yen. De oorkonde getuigt, naar het oordeel van Krom, van een maatschappij die in haar fijne en minutieuse organisatie niet bij de gelijktijdige MiddenJavaansche ten achter stond ${ }^{4}$ ).

In de nieuwe geschiedenis der T'ang dynastie werd, naar wij zagen, gesproken van "those of Dva-ha-la and Dva-pa-tan". Dva-ha-la is Janggala, de ligging daarvan is nauwkeurig te bepalen.

Toen koning Air langga omstreeks het midden der 11e eeuw zijn rijk onder zijn beide zonen verdeelde, verkreeg de eene Kaḍiri of het westelijk, de andere Janggala of het oostelijk deel. In ruimen zin was dus Janggala alle gebied dat onder het oostelijk rijk ressorteerde, het eigenlijk gezegde Janggala vormde daarvan een deel en het kerngebied. 't Is geheel hetzelfde als wanneer men nu spreekt van de residentie Kaḍiri, genoemd naar het landschap van dien naam en

1) R. Goris, De Oud-Javaansche inscripties uit het Sri-Wědari museum te Soerakarta, in: Oudheidkundig verslag 1928 blz. 63 v.v., speciaal blz. 68 .

2) Natuurlijk op koper. $\mathrm{Er}$ is in deze alluviale vlakte op velden noch wegen een steen te bekennen waarop een inscriptie zou kunnen worden gebeiteld. - Zie voor de ligging van Waru, Kĕboan pasar en in de oorkonde genoemde plaatsen, Topografische kaart residentie Soerabaja, schaal $1: 20000$, detailbladen $\mathrm{MX}, \mathrm{XI}$.

3) J. L. A. Brandes, Oud-Javaansche Oorkonden IX, Verh. Bat. Gen. LX. - Krom o.c.p. 156.

4) Krom o.c.p. 156. - W a h a r u voor w a r u is kanselarijtaal, cf. Tag. Bis. b a go. 
afdeeling waar de zetel des bestuurs is gevestigd en gevormd door deze met omliggende afdeelingen die ieder weer een eigen naam dragen. Er kan van een aangrenzend gewest een landstreek bijkomen of daarheen een afgaan, de naam blijft dezelfde. Zoo heeten, of heetten tot voor kort, de meeste residenties, historische landschappen, naar haar kerngebied.

Janggala nu, in engeren zin, was de Brantas-delta. „Wanneer de „,vorst in Janggala is, houdt hij steeds hof te Surabaya”, zegt de Nāgara kṛtāgama ${ }^{1}$ ). De hoofdstad lag daar dus buiten, en wel in Japan, zie beneden. Janggala wordt ook onderscheiden van Pasuruhan $^{2}$ ).

$\mathrm{Na}$ de restoratie van het Nederlandsch gezag bestond de Brantasdelta van 1817 tot 1859 , met uitzondering van de stad Soerabaja en wat daaraan grensde en een strook langs de Porong (Rawapoelo I en II) uit de districten Djanggala 1-IV. In laatstgenoemd jaar werd dit gebied tot een afzonderlijke afdeeling verheven, Sidakare in Djanggala II werd hoofdplaats onder den naam Sidaardja, de nieuwe afdeeling kreeg denzelfden naam en er werd een nieuwe districtsindeeling ingevoerd. Thans weet de landbouwer niet meer dat de grond der vaderen minstens dertien eeuwen lang Janggala geheeten heeft. Zoo verdwijnt door een enkel regeeringsbesluit de historie onder onze oogen. Bij desavereenigingen gaat het escamoteeren nog gemakkelijker.

Een haven diende om tot bloei te komen, in het Oosten aan twee voorwaarden te voldoen: de schepen moesten er een veilige ligplaats vinden en zij moesten er kunnen ververschen. De haven van ,Jurtan” wordt nog in 1600 door Jacob van Heemskerck, naar wij boven zagen, als de beste van Java beschreven. De vruchtbare Brantasdelta vormde een achterland dat alle waren waaraan de schepen behoefte hadden, kon verschaffen. $\mathrm{Zij}$ konden tesamen tot bloei komen.

Tot dusverre was de steen van Dinaya het oudste gedenkteeken van Hindoe-kolonisatie in Oost-Java (760). Thans blijkt dat reeds een eeuw eerder Tamil-sprekende Indiërs zich daar gevestigd hadden, komende uit datzelfde Zuiden van Indië vanwaar de Agastya-ver-

1) Nāgarakṛtāgama $17: 5$, ed. Krom, p. 59. - 's-Gravenhage 1919.

2) idem, zang $18: 5$, p. 65 .

D1. 102. 
eerders van Dinaya afkomstig waren $\left.{ }^{1}\right)^{2}$ ).

De Javanen laten zich in de namen $\mathrm{Ja}$ (ya) wārttam en Janggala niet hooren, maar zij moeten er geweest zijn, want wie anders kunnen het land hebben bebouwd dan zij?

II.

't Is nog slechts weinige jaren geleden dat men ter reede van Grěsik zeilschepen kon zien liggen die de vaart met Soerabaja onderhielden, mogelijk is dat nog het geval. Maar de tijd schijnt niet ver meer dat zij geheel verdwenen zal zijn. De schepen kunnen den strijd tegen moderne verkeersvormen niet volhouden.

Valentijn zegt nog in 1700 dat de plaats zeer sterk bevaren werd, de handel in rijst, zout en andere waren was er ongemeen groot ${ }^{3}$ ).

Een eeuw vroeger was zout een belangrijk uitvoerartikel, geheel Java werd er van voorzien (Djapara, Bantěn). Dit zout werd ongetwijfeld in de nabijheid gewonnen. De omgeving van Grěsik en Madoera bieden de gunstige geologische en klimatologische omstandigheden voor het aanleggen van zoutpannen en het winnen van zout.

Uit de aangehaalde berichten der oude Nederlanders bleek reeds

1) Thans wordt Tamil gesproken aan de Oostkust van het Voor-Indisch schiereiland van Pulicat benoorden Madras tot kaap Comorin en van de zee landwaarts tot de Ghãt's, de zg. Carnatic plain, en aan de Westkust van kaap Comorin noordwaarts tot in de buurt van Trivandrum, ten Westen van de Ghāt's, Caldwell o.c. Introduction p. 9.

2) In „Deux itinéraires” vermeldt de heer Pelliot een mededeeling in de geschiedenis der eerste Sung dynastie (420-478) voorkomende, welke luidt dat het koninkrijk Ho-lo-tan op het eiland Chö-p'o in de 5e eeuw meermalen gezanten naar den Chineeschen keizer afvaardigde. In 435 kwam er een gezantschap van Chö-p'o-p'o-ta. Deze naam komt in de door hem geraadpleegde uitgave van den boekhandel. T'ou chou tsi tch'eng op driëerlei wijze voor: in de Annalen als Chö-p'o-so-ta, in de notities van vreemde landen als Chö-p'o-p'o-ta en in de tabel als Chö-p'o-ta. Een ander werk, de Nan-che heeft in de eigenlijk gezegde Annalen Chö-p'o-so-ta, maar in de notities en in de tabel Chö-p'o-ta (o.c.p. 273). De teekens voor p'o en so toonen gelijkenis. 't Is verleidelijk voor Chö-p'o-p'o-ta te lezen: Jawa (liever: Yawa, o.c.p. 268) [Ja(ya)]wärttam, ja(ya) zou dan zijn uitgevallen of weggelaten. Jawa is de benaming van wat bij de Javanen en Soendaneezen zoo heet: het land der Javanen, de Javalanden zonder Soenda, ook bij de Chineezen is Chö-p'o de Java-landen. [ $\mathrm{Ja}(\mathrm{ya})]$ wārttam kan nadere aanduiding van een onderdeel zijn, ter onderscheiding van Ho-lo-tan, Oost-Java contra Midden-Java. Het land had een koning die Cho-li-p'o-ta-t'o-a-la-pa-mo (= ${ }^{\circ}$ warman) heette (Groeneveldt o.c.p. 135). 't Geval is echter te onzeker - ook ta (oud *t a t, Pelliot o.c.p. 274) voor tam is aan bedenking onderhevig - om er conclusies aan te kunnen verbinden.

3) Valentijn IV, I 46. 
dat Djoewartan-Grěsik de specerijen-markt van den Archipel was (boven blz. 3).

In de $16 \mathrm{e}$ eeuw waren de Portugeezen de Nederlanders voorgegaan. De Javanen haalden de specerijen uit den Grooten Oost ${ }^{1}$ ) en de Portugeezen kwamen naar Grěsik om ze te koopen, de Nederlanders troffen hen daar aan.

De graftomben van Cambaysche makelij van Malik Ibrahim $\dagger 1419$ en anderen spreken van handelsbetrekkingen met Goedjarat en scheepvaartverkeer tusschen Grěsik en Cambay. Chineesche berichten gewagen van grooten handel in Grěsik in dezen zelfden tijd ${ }^{2}$ ).

Chau Ju-Kua zegt in zijn werk, dateerende van het midden der 13e eeuw, over Su-ki-tan sprekende: „The country of Ta-pan „,connects to the east with Great Shö-p'o. It is also called Jung-ya-lu „(Also written Chung-ka-lu, H en R) .... The country being a level „plain, intersected by an anchorage, there is trade both by water and ,by land.

,The native products are bay-salt, sheep and parrots" 3 ).

Ta-pan is Japan, 't landschap heeft zijn naam tot 1838 behouden (naar nieuwere spelling Djapan), in welk jaar het werd omgezet in de afdeeling Madjakěrta met de districten Madjakěrta en Madjasari; ook de hoofdplaats Djapan veranderde van naam en werd Madjakěrta. In Djapan lagen de ruinen van Madjapait. Prapanca noemt den naam niet, maar zegt wel dat Majhapahit buiten Janggala lag (boven blz. 8 vv.). Chau Ju-kua neemt hier Japan en Janggala tesamen, na ze even tevoren als twee onderscheiden onderhoorigheden van Shö-p'o (Fransche transcriptie Chö-p'o) te hebben genoemd. Hij stelt Groot-Java ten Oosten daarvan, dus in Pasuruhan-Malang. 't Is een benaming van eigen vinding waartoe hij, naar het schijnt, gekomen is om de "nagaraging" van Tumapēl aan te duiden.

Wat ,the native products" betreft, kan het vervaardigen van zout uit zeewater alleen op Grěsik zien. Ook zout van Madoera kan via deze haven (Jawartan) zijn weg naar elders gevonden hebben, het eiland wordt niet afzonderlijk genoemd. Omtrent schapen valt niets te zeggen, men vindt thans overal op Java schapenteelt op kleine schaal, maar in de eene streek niet meer dan in de andere. Papegaaien .werden uit het Oosten van den Archipel aangevoerd, dit wijst weer

1) P. E. Tiele, De Europeërs in den Maleischen Archipel II, Bijdr. Kon. Inst. 4, III, 14.

2) Ying-shai Shêng-lan (1416), Groeneveldt o.c.p. 173.

3) Chau Ju-Kua o.c.p. 84. 
op Grěsik. Men moet dus de zinsnede over de ,native products” als behoorende bij Tapan lezen, al luidt de titel van het hoofdstuk Su-ki-tan.

In het hoofdstuk over Shö-p'o heet het: „It is a broad and level „,country, well suited to agriculture... . The people pay a tithe-rent. „They make salt by boiling seawater. The country also abounds in „fish, turtles, fowl, ducks, goats ....

„They have also elephants' tusks, rhinoceros horns, pearls, cam„phor, tortoise-shells, sandalwood, aniseed, cloves, cardamoms, cubebs, „lakawood, mats, foreign sword blades, pepper, betelnuts, sulphur, „saffron, sapan-wood and parrots" ${ }^{1}$ ).

Het is duidelijk dat Chau Ju-Kua het hier over dezelfde streek heeft, misschien zonder dat het hem zelf bewust was, maar de feiten zijn juist. Het maken van zout uit zeewater ziet weer op Grěsik, schildpadden, versta: landschildpadden, zijn nu nog in de Brantasdelta overvloedig. De schapen zijn nu geiten geworden. Olifantstanden werden naar de Kleine Soenda-eilanden verhandeld, men bracht vandaar sandelhout terug, Ti-wu $=$ Timor en Ta-kang, niet geidentificeerd, worden onder de onderhoorigheden van Shö-p'o genoemd ${ }^{2}$ ) en waren de sandelhout-leverende landen ${ }^{3}$ ). Waar de parels vandaan kwamen is moeilijk te zeggen, maar wel weten wij door de Ying-yai Shêng-lan (1416) dat er in Grěsik „precious stones” in groote hoeveelheden verhandeld werden ${ }^{4}$ ). De kruidnagelen kwamen uit den Grooten Oost, evenals de papegaaien die hier weder verschijnen. Noot-muskaat wordt niet genoemd, dit is een onwillekeurige omissie: in het over de noot-muskaat handelende hoofdstuk zegt de schrijver toch, dat zij ,,were brought from the foreign tribes in the „depths of the islands of Huang-ma-chu and Niu-lun" ${ }^{5}$ ). De beschrijving deugt niet, maar beide eilanden waren onderhoorigheden van Shö-p'o (p. 83). Ook deze specerij kwam dus in JawartanGrěsik ter markt.

In den aanhef van het hoofdstuk over Su-ki-tan zegt Chau Ju-Kua : „Su-ki-tan is a branch of the Shö-p'o country. To the west it borders "on Sin-t'o, to the east it adjoins Ta-pan" ${ }^{6}$ ). Indien Sin-t'o Soenda is, zou men het dus in Midden-Java zoeken, in allen gevalle westelijk

a) Chau Ju-Kua o.c.p. 77, 78.

2) Chau Ju-Kua o.c.p. 83 .

3) Chau Ju-Kua o.c.p. 208.

4) Groeneveldt o.c.p. 173 .

5) Chau Ju-Kua o.c.p. 210.

6) O.c.p. 82 . 
van Japan. Doch Groot Shö-p'o lag oostelijk van Japan, tegelijkertijd heet het koninkrijk Shö-p'o ook P'u-kia-lung $=$ Pakalongan ${ }^{1}$ ). Volgens een late, Chineesche bron, de Tung Hsi Yang K'au (1618) is Sukitan een onderhoorigheid van Java met vele verschillende nederzettingen waarvan Grěsik de voornaamste is. De aangrenzende landen zijn surabaya en Tuban $^{2}$ ).

Rouffaer heeft betoogd dat Su-ki-tan Jav. su ěta n was, van s uk ět-bosch (KB Wb.), struikgewas, wildernis, bosch, gras (Jb.), dus sukětan is: met struikgewas begroeid enz.; hij stelt dit gelijk met janggala ${ }^{3}$ ). Chau Ju-Kua weet te vertellen, dat de Chineesche kooplieden den naam Shö-p'o in Su-ki-tan veranderd hadden om het Chineesche hof dat herhaaldelijk den handel met dat land verboden had, om den tuin te leiden ${ }^{4}$ ). Wanneer dat de bedoeling was, hadden de Chineezen zelf wel een naam kunnen bedenken. Doch aangenomen dat Su-ki-tan inderdaad sukětan was, dan is het toch stellig niet Janggala, dat Chau Ju-Kua juist van Su-ki-tan onderscheidt, zooals uit bovenstaande aanhalingen genoegzaam blijkt. Chau Ju-Kua is in hetgeen hij over beide landen zegt, verward. De zaak is dat hij uit het verstoppertje spelen niet wijs is kunnen worden en gegevens uit verschillende streken dooreen heeft gekludst; strict genomen niet eens onjuist want het is duidelijk dat achter den naam Su-ki-tan meer dan één streek van het verboden land verscholen ging.

Dat Java een stapelplaats van den specerijenhandel was, wordt bevestigd door Marco Polo. Hij zegt dat Java specerijen voortbrengt, een gewone vergissing zooals ook de Chineezen wel maken door een artikel dat in een haven verkregen wordt voor een product van het land aan te zien. Java bracht de specerijen niet voort, maar was er de markt van ${ }^{5}$ ). Het scharnier waarom zich deze specerijen-handel bewoog, is door Chau Ju-Kua in Oost-Java aangewezen met Jawar$\tan$ - Grĕsik als havenplaats.

Ibn Chordādhbeh (846) vermeldt: „De ces îles ${ }^{6}$ ) on arrive après ,quinze jours de navigation aux iles des aromates" ${ }^{7}$ ). Terecht heeft

1) O.c.p. 75.

2) Groeneveldt o.c.p. 179.

3) G. P. Rouffaer, Was Malaka imperium vóór 1400 A.D., genaamd Malajoer? in: Bijdr. Kon. Inst. 77 blz. 135 v.v.

4) O.c.p. 78.

5) Sir Henry Yule, The book of Ser Marco Polo, 3e druk, II 272 v.v. Londen 1929.

6) Djāba en 2 andere niet ver daarvandaan te zoeken eilanden.

7) Aangehaald door Rouffaer in Encyclopaedie van Nederlandsch Indië (1e druk) s.v. Tochten, blz. 369. 
Rouffaer erop gewezen dat hier van de Javaansche Molukken-moesson-vaảrt gesproken wordt. Als uitgangspunt komt alleen Oost-Java in aanmerking.

In het jaar 647, zegt de oude geschiedenis der T'ang dynastie, zond de koning van Dva-pa-tan gezanten tot den Keizer, zij brachten als tribuut katoenen kleeding, olifantstanden en witte sandel ${ }^{1}$ ). - Wanneer in dat land dooden werden afgelegd, werd de mond met goud gevuld, gouden armbanden werden om armen en beenen gelegd, kamfer-olie, kamfer en andere parfumerieën werden toegevoegd, het lijk werd daarna verbrand.

Oilifantstanden, sandelhout, kamfer kwamen van elders, Ja(ya)wārttam dreef dus uitgebreiden zeehandel. 't Valt op hoe constant het handelsverkeer is, immers, deze zelfde artikelen noemt zes eeuwen later Chau Ju-Kua. Specerijen ontbreken, maar die schijnen nooit voor tribuut aan den Keizer in aanmerking te zijn gekomen ${ }^{2}$ ).

De schepen die, schakelsgewijze, het verkeer tusschen Indië en China over zee onderhielden, deden Java niet aan, daarvoor lag het te ver uit de route. $\mathrm{Er}$ moeten speciale redenen geweest zijn die vreemde kooplieden bewogen naar Oost-Java te varen. 't Lijkt mij mogelijk, zoo niet waarschijnlijk, dat toen reeds de specerijen der Molukken daar werden aangebracht. 't Is niet meer dan een gissing waarvoor echter de continuiteit van handelswegen, ook in Jawartan's handel opgemerkt, pleiten kan. Daarin komt eerst verandering als de Oost-Indische Compagnie verschijnt en alles onderste boven gooit. Een dergelijke radicale verandering in de machtsverhoudingen heeft zich, voor zoover wij thans weten, tusschen 650 en 850 ( Ibn Chordādhbeh) niet voltrokken.

Maar moge het dan al zoo zijn dat Indische kooplieden zich in de Brantas-delta hebben nedergezet om dichter bij het land van belofte te zijn, zij moeten vergezeld of gevolgd zijn door landgenooten van alle rangen en standen, daarvan getuigen de steen van Dinaya (760) en de oorkonde van Kĕboan pasar (873).

't Vermoeden is uitgesproken dat de Agastya-vereerders van Dinaya naar het Oosten uitgeweken lieden van Midden-Java zouden zijn, waar immers in 732 bij Canggal in Kĕḍoe een oorkonde was opgericht, waarbij de koning Sanjaya zijn Çiwa-vereering tot Kunjara

1) Groeneveldt, o.c.p. 183.

2) Slechts eenmaal vind ik vermeld dat ,they" van Java 75000 kati peper zonden (1381), Geschiedenis van de Ming dynastie (1368-1643), Groeneveldt o.c.p. 162 . 
kunja terugbracht ${ }^{1}$ ). 't Ligt thans echter meer voor de hand in de mannen van Dinaya de rechtstreeksche nazaten der kolonisten van de Brantas-delta te zien. Ook deze laatsten moeten in het midden der 7 e eeuw daar reeds eenigen tijd gevestigd zijn geweest ${ }^{2}$ ).

De in den aanhef vermelde legende die een voorname handelaarster, van buiten Java gekomen, zich in een eigen kampong van Grěsik deed vestigen, heeft de waarheid wel goed bemanteld.

1) Krom o.c.p. 120 v.v., 141 v.v.

2) Vgl. boven, blz. 548 noot 1 .

Leiden, 23 Augustus 1943. 